\title{
Informed consent in HIV prevention trials: Highlights from an international workshop
}

Population Council

Follow this and additional works at: https://knowledgecommons.popcouncil.org/departments_sbsr-hiv

Part of the Health Services Research Commons, Immune System Diseases Commons, International Public Health Commons, Medicine and Health Commons, Public Health Education and Promotion Commons, Quantitative, Qualitative, Comparative, and Historical Methodologies Commons, and the Virus Diseases Commons How does access to this work benefit you? Let us know!

\section{Recommended Citation}

"Informed consent in HIV prevention trials: Highlights from an international workshop." New York: Population Council, 2008. 


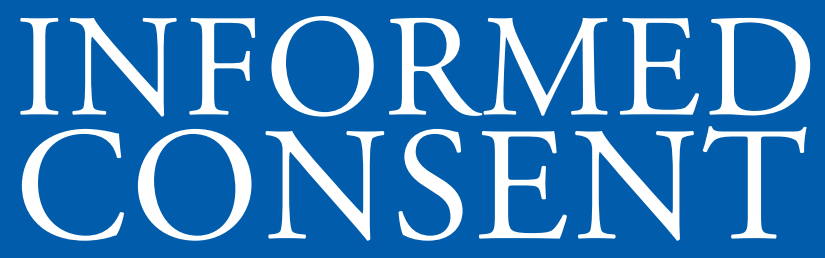

IN HIV PREVENTION TRIALS HIGHLIGHTS FROM AN INTERNATIONAL WORKSHOP 


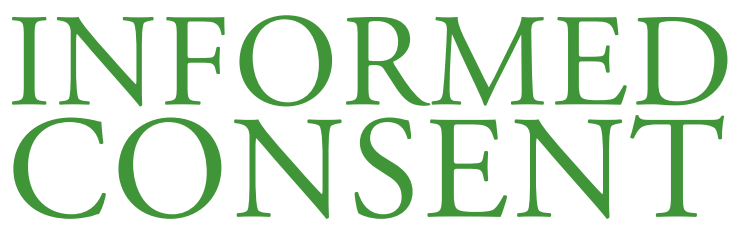

IN HIV PREVENTION TRIALS HIGHLIGHTS FROM AN INTERNATIONAL WORKSHOP 
Copyright (C) 2008 The Population Council, Inc.

\section{Population Council}

The Population Council conducts research worldwide to improve policies, programs, and products in three areas: HIV and AIDS; poverty, gender, and youth; and reproductive health.

One Dag Hammarskjold Plaza

New York, NY 10017 USA

Telephone: 212-339-0500

Fax: 212-755-6052

\section{Acknowledgments}

The workshop on informed consent in HIV prevention trials, held 16-18 May 2005 in New York City, was conceptualized and planned by a committee that comprised Barbara Friedland, Martha Brady, and Hillary Bracken (Population Council), Kathleen MacQueen (Family Health International), Cynthia Woodsong (Research Triangle Institute), and Elizabeth McGrory (consultant). The workshop was cohosted by the Population Council and Family Health International and was supported by the United States Agency for International Development, International Partnership for Microbicides, Inc., National Institutes of Health, and the William and Flora Hewlett Foundation.

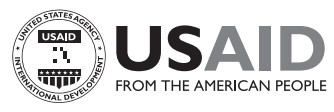

This brief is made possible by the generous support of the American people through the United States Agency for International Development (USAID). The contents of this brief are the sole responsibility of the Population Council and do not necessarily reflect the views of USAID or the United States Government.

Any part of this brief may be copied or adapted to meet local standards without permission from the Population Council, provided that the parts copied are distributed free or at cost (not for profit) and that the source is identified. Any commercial reproduction requires prior permission from the Population Council. The Population Council would appreciate receiving a copy of any materials in which the text is used.

www.popcouncil.org/pdfs/ICWorkshopHighlights.pdf 


\section{Contents}

Introduction

Informed consent tools: Communicating difficult concepts

Booklets

Videos

Interactive computer-based participant education

Explaining difficult concepts

Assessing comprehension among trial participants:

What do participants need to know?

The importance of training

Conclusion

Appendix 1: Quantitative and qualitative approaches

Appendix 2: HPTN 035 trial: Enrollment informed consent comprehension checklist (Excerpted) 


\section{Introduction}

T $\mathrm{n}$ the rapidly evolving arena of HIV prevention clinical trials, informed con1 sent is recognized as a critical dimension of making ethics operational. While ensuring informed consent and voluntary participation is one of the most complicated aspects of any clinical trial, HIV prevention trials, many of which are being conducted in resource-poor settings, pose even greater ethical and practical challenges:

- Large-scale efficacy trials need to be conducted in areas with a high incidence of HIV.

- Trials require healthy volunteers, who often are economically and socially vulnerable and at substantial risk of HIV infection.

- Researchers must reinforce the unknown efficacy of test products so that participants do not feel a false sense of protection, or "therapeutic misconception," which could lead to increased risk behaviors (reducing condom use or increasing numbers of partners).

- HIV/AIDS prevention trials involve highly sensitive issues: stigma, sexuality, and gender-based power dynamics.

- Conveying technical research terms and unfamiliar concepts in local languages can be difficult.

These challenges are exacerbated in settings of low literacy, where potential research participants may have little understanding of sexual health or clinical research.

To address these challenges, the Population Council and Family Health International (FHI) convened a meeting to identify successful approaches to the informed consent process that could be adapted and shared widely among researchers implementing HIV prevention trials. This brief, adapted from the full meeting report, ${ }^{1}$ focuses on innovative tools and strategies being used to facilitate informed consent in HIV prevention trials, and incorporates illustrative examples from completed and ongoing trials.

\footnotetext{
${ }^{1}$ C. Elizabeth McGrory, Barbara A. Friedland, Cynthia Woodsong, and Kathleen M. MacQueen. 2006. Informed Consent in HIV Prevention Trials: Report of an International Workshop. New York: Population Council and Family Health International. Available at: www.popcouncil.org/pdfs/ ICWorkshop.pdf.
} 


\section{Informed consent tools: Communicating difficult concepts}

T nvestigators in a number of current HIV prevention studies are investing in a 1 range of creative tools and approaches to improve study volunteers' understanding of research concepts and trial procedures, including study booklets, fact sheets, flip charts, videos, visual aids, and interactive computer-based participant education. ${ }^{2}$

\section{Tips for developing informed consent materials and approaches}

- Conduct careful formative research: draft, pretest, and adapt to local settings.

- Engage study staff, community advisory board members, potential participants, and, if possible, participants from earlier studies in generating ideas, developing approaches, and pretesting materials.

- Draw on community advisory boards and other community structures to reinforce key concepts, such as voluntarism, and to assist with developing language, terms, and analogies that convey research concepts that are relevant and understandable in the local setting.

- Use materials in combination to build on and reinforce each other in presenting relevant information to the community and participants throughout the clinical trial process.

\footnotetext{
${ }^{2}$ Interactive technologies can include ACASI — audio computer-assisted self-"instruction" or self-"interview"either used to provide information to study volunteers or as an interview technique for eliciting responses on sensitive topics.
} 


\section{Booklets}

well-produced booklet conveys a trial's professionalism and respect for par-
ticipants. Lifelike color illustrations may help participants understand and
retain information. Study booklets can be beneficial for:

- providing general or detailed information to research participants about the study steps and procedures, and for supplementing informed consent forms;

- defining and illustrating complex research concepts graphically;

- responding to questions during information sessions;

- helping with recruitment if participants show booklets to friends or relatives.

Informed consent tools in practice: Population Council Phase 3 Carraguard ${ }^{\circledR}$ trial The Population Council's Carraguard ${ }^{\circledR}$ Phase 3 microbicide trial $^{3}$ booklet supplemented the informed consent form. During pre-testing, participants voiced opinions about the images, color, and overall quality of the booklet, leading to design changes (see box).

\section{Informed consent tools in practice: HPTN 035 microbicide trial}

The booklet for the HIV Prevention Trials Network's (HPTN) 035 microbicide trial $^{4}$ uses line drawings of a character named Serena to explain many of the study's concepts and procedures. This multisite trial was conducted in several countries, so materials were pilot tested and adapted to each setting. Although Serena was intentionally designed to look familiar to the population of women being recruited for the trial, pretesting resulted in Serena being redrawn to appear more modern, attractive, and affluent. Further, one drawing of Serena was interpreted by many potential participants as appearing worried and was subsequently redrawn (see box).

\footnotetext{
${ }^{3}$ A Phase 3 safety and efficacy trial of the microbicide Carraguard to prevent HIV seroconversion in women was conducted at three sites in South Africa between March 2004 and March 2007. www.popcouncil.org/projects/MIC_CarraClinicalStudies3.html. Accessed 17 January 2008.

${ }^{4}$ The HPTN 035 trial is a four-arm randomized Phase $2 / 2$ b safety and effectiveness trial of two candidate microbicides and two control arms that enrolled 3,220 women in eight sites in five countries. www.hptn.org/research_studies/hptn035.asp; www.mtnstopshiv.org/node/62. Accessed 17 January 2008.
} 
Adaptation of Carraguard Phase 2 booklet for Phase 3

Phase 2

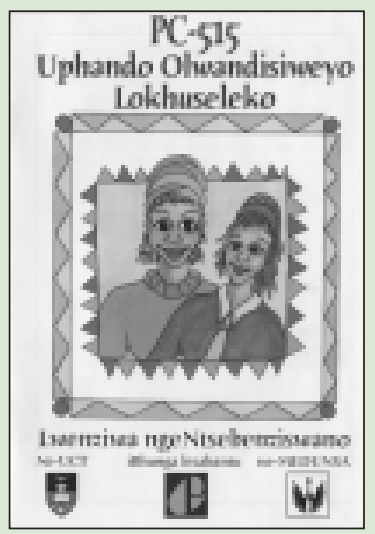

Phase 3

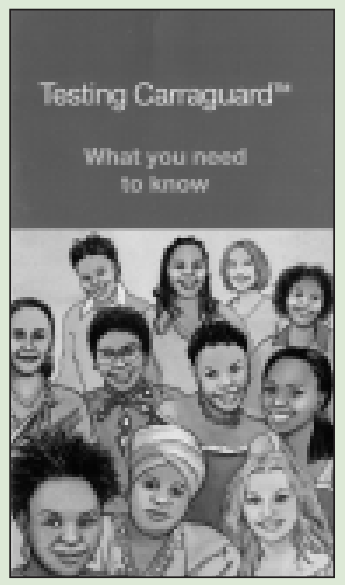

Study participants in the Phase 2 Carraguard trial recommended that illustrations for the information booklet (left) be more realistic. Changes were made to the Carraguard Phase 3 booklet (right).

Evolution of "Serena” for HPTN 035
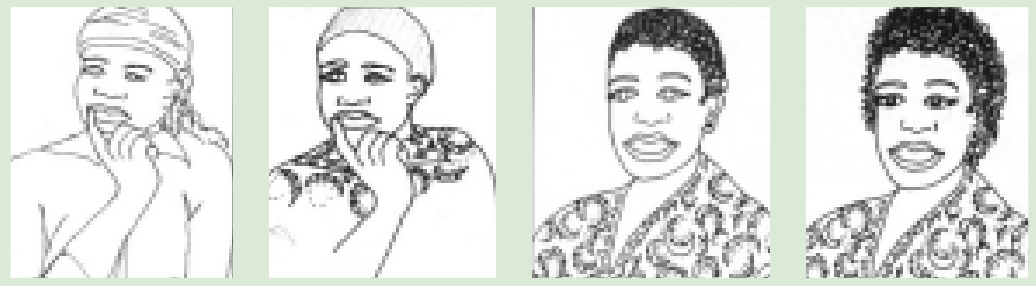

In pretests, participants helped to develop Serena, used in the booklets for the trial. (Artwork by Denise Todloski) 


\section{Videos}

Tideos offer the potential of facilitating recruitment and informed consent processes, particularly in large-scale trials. Videos can be more engaging than print media, may be an especially useful tool in settings with low literacy, and can help in standardizing provision of trial information and reducing the burden on study staff.

\section{Challenges for video technology include:}

- The complex development process requires a long lead time, which can make it difficult to accommodate protocol changes.

- Showing a video may not be feasible at all recruitment locations since bringing expensive equipment to local sites can be cumbersome or even dangerous.

- Attracting the attention of potential participants in busy clinics may be difficult.

Informed consent tools in practice: MIRA study of the latex diaphragm to prevent HIV infection in women

MIRA trial ${ }^{5}$ staff found that participants tended to be bored by written materials or by hearing staff present information; volunteers indicated that a video would help keep them engaged.

- Clinicians, community members, and the research team were involved in developing the video.

- Trial participants responded positively to the appearance in the video of the chair of the ethics committee, which:

-helped to give a real face to the concept of the "ethical review";

-sent the message that participants are valued;

-conveyed the study's professionalism.

\footnotetext{
${ }^{5}$ The MIRA (Methods for Improving Reproductive Health in Africa) trial is being conducted in Durban and Johannesburg, South Africa, and Harare, Zimbabwe. www.cervicalbarriers.org/documents/ MIRA_Results_and_Publications_aug07_final_pdf.pdf. Accessed 17 January 2008.
} 
Informed consent tools in practice: Population Council Phase 3 Carraguard trial To inform approaches for the Phase 3 efficacy trial of Carraguard ${ }^{\circledR}$ in South Africa, the Population Council conducted focus-group discussions and in-depth interviews with Phase 2 trial participants and staff. ${ }^{6}$ The Council sought to identify ways to explain difficult concepts and solicited suggestions for the recruitment and informed consent processes for the Phase 3 trial. On the basis of the responses, the Population Council developed a video ${ }^{7}$ to clarify unfamiliar concepts and to present basic information in a more engaging manner.

- Vignettes were used to convey difficult concepts and key themes such as randomization, double blinding, voluntary participation, partner communication, the pelvic exam (an unfamiliar procedure for most women in the trial communities), and HIV testing.

- An educational consultant helped to develop the script, and a well-known actress appeared as the on-camera narrator.

- Sections of the video were pretested and adapted following focus-group discussions with women in the trial communities and with community advisory board members.

- Anecdotal reports suggest that study staff and trial participants found the video informative and interesting; women appreciated seeing in advance what they would experience in the trial.

\footnotetext{
${ }^{6}$ A. De Kock, M. Marumo, and B. Friedland. 2005. "Carraguard Phase 3 Trial: Developing and implementing a video." Presentation at the Population Council/Family Health International Workshop on Informed Consent in HIV Prevention Trials, New York, 16-18 May.

7 “Testing Carraguard ${ }^{\mathrm{TM}}$. What you Need to Know." Video. Johannesburg: Population Council, 2004. Produced by Pandamonium Productions. www.popcouncil.org/media/saclips/videolink.html. Accessed 17 January 2008.
} 


\section{Interactive computer-based participant education}

\section{Informed consent tools in practice: BOTUSA Project PrEP trial}

The BOTUSA Project PrEP trial ${ }^{8}$ presented a plan for using interactive computerassisted self-instruction as reinforcement after an intensive face-to-face consenting process and prior to administration of a comprehension test. The technology employs a touch-screen computer with an audio component, and information about the trial is communicated in a multimedia presentation with an accompanying narration; participants have the option of selecting a language.

\footnotetext{
${ }^{8}$ The Botswana PrEP Trial, a study to evaluate the safety and efficacy of pre-exposure prophylaxis in reducing HIV infection among heterosexual young adults, is being conducted by the BOTUSA Projecta collaboration of the Botswana Government and the U.S. Centers for Disease Control and Prevention (CDC). www.cdc.gov/hiv/resources/factsheets/prep.htm. Accessed 17 January 2008.
} 


\section{Explaining difficult concepts}

linical trial concepts and research terms are particularly difficult to convey to study volunteers in diverse settings and languages in a way that ensures understanding. Trial staff are employing innovative approaches to present information and explain complex concepts in educational and informed consent materials used in local settings., 10

Examples of innovative ways for explaining difficult concepts discussed at the meeting include:

Randomization: A procedure for dividing participants into treatment groups by random allocation, used to eliminate selection bias by researchers or participants, ensure that statistical analysis of data will be valid, and create groups compatible with respect to factors that could influence outcome. Randomization is a complex research concept that may be unfamiliar to potential participants and is difficult to explain consistently in diverse settings:

- Randomization is often explained by using images associated with the notion of chance, such as a lottery machine or rolling dice (see box).

- An image of a computer can make the point that a computer program, rather than a person, randomly assigns a trial participant to the intervention or control group.

\section{Randomization}
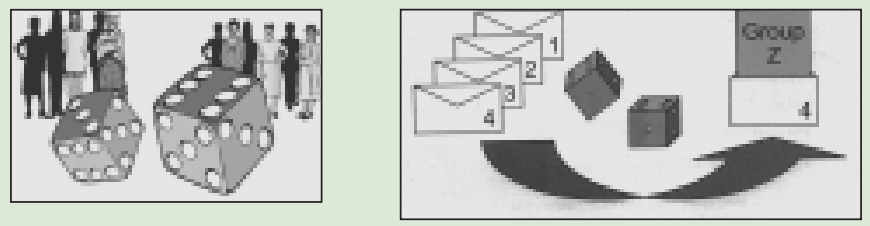

Images of objects associated with the idea of chance-rolling dice-were used to explain that participants are selected randomly for a study's intervention and control groups. Left, illustration from the Carraguard Phase 3 trial; right, from the BOTUSA PrEP trial.

\footnotetext{
${ }^{9}$ H. Bracken. 2005. "Communicating complex concepts." Presentation at the Population Council/Family Health International Workshop on Informed Consent in HIV Prevention Trials, New York, 16-18 May.

${ }^{10}$ Because the effectiveness of these methods for conveying information to trial participants has not been systematically evaluated, they should be considered suggestions rather than "best practice."
} 
Placebo: Explanations emphasize that the study product and the placebo are identical except that the placebo:

- Is "inactive," or "doesn't have [name of active ingredient] in it"

- "One contains [the active ingredient] and one does not"

- Is a "comparison gel" (see box)

Other ways to explain placebos include analogous images that should be drawn from and tested in the local context to ensure that the example is relevant:

- Vitamin-enriched juice or milk

- Costume jewelry versus real gemstones

- Imitation colas versus Coke $^{\mathrm{TM}}$

Serodiscordance: It can be particularly difficult to convey the concept that one partner can be HIV positive and the other HIV negative. To encourage couples to be tested for HIV, the Partners in Prevention HSV/HIV trial ${ }^{11}$ uses an analogy of baobab trees infected with termites (see box). One cannot tell from afar which tree has termites nor which partner has HIV without testing. The baobab tree analogy will be appropriate in some settings but not relevant in others, illustrating the importance of pretesting and adapting images and language in each setting to ensure that they convey relevant messages and facilitate understanding.

Sensitive issues: Sexuality and other sensitive issues are addressed through either explicit or suggestive images (see boxes):

- Some materials use drawings such as shoes or clothes by a bed (without depicting people) to suggest sexual activity.

- Others use a more explicit drawing of a nude man and woman lying together.

- Similarly, the pelvic exam can be depicted in explicit or less graphic images.

- One trial includes the pelvic exam illustration only in materials used at the clinic site but not in materials that participants take home, to address the concern that explicit depictions in printed materials could be seen by other people and may stigmatize the study or the participants.

\footnotetext{
${ }^{11}$ A Phase 3 trial of acyclovir for HSV-2 suppression among HIV-discordant couples, being conducted in multiple sites in Africa by the Partners in Prevention project (University of Washington). http://clinicaltrials.gov/show/NCT00194519; http://depts.washington.edu/hsvhiv/public/index.html. Accessed 17 January 2008.
} 


\section{Placebo}

\section{Carraguard + condoms}

\section{Comparison gel + condoms}
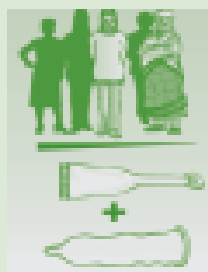

Animation in the Carraguard Phase 3 video emphasized that the product and the placebo look the same and are used in the same way.

\section{Pelvic exam}
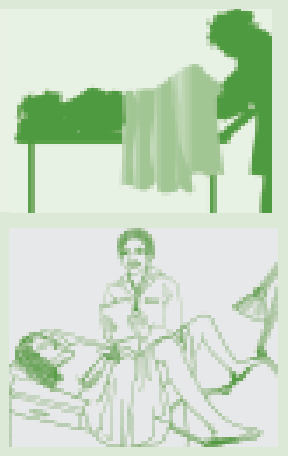

Some participants expressed concern that being too explicit in materials that may be taken home or seen by other people may stigmatize the study or the participants. Top picture from BOTUSA Project PrEP trial; bottom from HTPN.

\section{Serodiscordance}

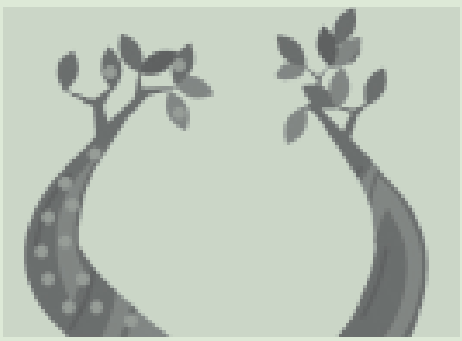

The two baobab trees look similar although one is infected with termites that can destroy one or both of the trees. The illustration is used as an analogy for HIV, which can infect one or both partners but cannot be diagnosed without testing. Illustration from Partners in Prevention HSV/HIV trial.

\section{Sexual activity}
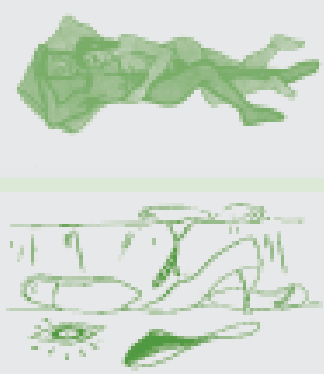

Depending on the study site, the materials in various Carraguard trials used explicit images (top-South Africa) or suggestive ones (bottom-Thailand) to suggest sex. 


\section{Assessing comprehension among trial participants: What do participants need to know?}

A s part of improving informed consent, many trial staff are grappling with A how to measure participants' understanding of trial issues. Researchers designing informed consent assessments confront a choice about whether to employ quantitative approaches or qualitative approaches (see Appendix 1).

- Should comprehension of specific concepts and study procedures be considered essential, such that volunteers must demonstrate their understanding before they are allowed to enroll?

- What methods should be used to assess comprehension?

Although a volunteer's full comprehension of all elements of a trial is the aim of informed consent, achieving this level of understanding may not always be possible. Many researchers considered a number of issues to be critical for trial volunteers to understand:

- Purpose of the research.

- Experimental nature of the study.

- Uncertainty about the test product's efficacy in preventing HIV infection.

- Need to continue other risk-reduction practices during participation in the study.

- Concepts of randomization, blinding, and placebos.

- Study procedures, risks, benefits, voluntarism, and confidentiality.

See Appendix 2 for an example of HPTN's comprehension assessment tool. 


\section{The importance of training}

- ven the best materials, tools, and assessments are of limited use if study staff are not given the training and support to use them appropriately and consistently. Developing and employing approaches for conveying complex issues and improving informed consent, and for evaluating their efficacy, can be costly and requires the resources and commitment of the trial sponsors, donors, and trial teams. Sufficient resources must be allocated in trial budgets for ongoing training and evaluation.

\section{Conclusion}

R esearchers and study staff across all settings should share strategies and tools R for maximizing and assessing participants' comprehension and improving informed consent. In addition to building evidence for continued investment, such exchanges also can contribute to resolving common challenges, from decisions about which media and strategies to use, to training, to specific approaches for conveying complex concepts. 


\section{Appendix 1: Quantitative and qualitative approaches}

\begin{tabular}{|c|c|c|}
\hline & Strengths & Weaknesses \\
\hline $\begin{array}{l}\text { Quantitative } \\
\text { Approaches } \\
\text { (closed-ended } \\
\text { questions, true/false, } \\
\text { multiple choice) }\end{array}$ & $\begin{array}{l}\text { - Better for eliciting specific } \\
\text { information, one-word } \\
\text { answers, or for checking } \\
\text { facts } \\
\text { - Simple to administer } \\
\text { - Evaluation is relatively } \\
\text { objective } \\
\text { - Requires less staff training }\end{array}$ & $\begin{array}{l}\text { - Limited for assessing comprehen- } \\
\text { sion of complex concepts } \\
\text { - Can create illusion that participant } \\
\text { has understood, while only meas- } \\
\text { uring short-term ability to repeat } \\
\text { information } \\
\text { - Choosing precise wording/terms } \\
\text { is complicated in multi-site } \\
\text { trials/multiple languages } \\
\text { - True/false and multiple choice } \\
\text { questions include incorrect state- } \\
\text { ments that can confuse } \\
\text { volunteers } \\
\text { - True/false assessments tend to } \\
\text { be skewed to "true" statements } \\
\text { - True/false approach not familiar in } \\
\text { many settings; volunteers may } \\
\text { consider it impolite to say that a } \\
\text { statement a counselor has made } \\
\text { is "wrong" }\end{array}$ \\
\hline $\begin{array}{l}\text { Qualitative } \\
\text { Approaches } \\
\text { (open-ended } \\
\text { questions) }\end{array}$ & $\begin{array}{l}\text { - Encourages people to say } \\
\text { more, ask questions, and } \\
\text { reveal more clearly whether } \\
\text { information has been } \\
\text { understood } \\
\text { - Allows participant to } \\
\text { respond in his/her own } \\
\text { words in a dialogue consis- } \\
\text { tent with the spirit of } \\
\text { informed consent } \\
\text { - Staff can get a sense of } \\
\text { whether a participant can } \\
\text { apply information to decid- } \\
\text { ing whether to participate in } \\
\text { a trial and to follow the } \\
\text { protocol }\end{array}$ & $\begin{array}{l}\text { - Evaluation is subjective; requires } \\
\text { more sophisticated and nuanced } \\
\text { judgment by staff of volunteer's } \\
\text { understanding } \\
\text { - Requires more extensive staff } \\
\text { training and ongoing support } \\
\text { - Requires greater staff time to } \\
\text { implement } \\
\text { - Enrollment targets may create } \\
\text { disincentive for staff to determine } \\
\text { that a volunteer does not under- } \\
\text { stand the information well enough } \\
\text { to enroll }\end{array}$ \\
\hline
\end{tabular}




\section{Appendix 2: HPTN 035 trial: Enrollment informed consent comprehension checklist, Version 1.0 (Excerpted)}

The HPTN 035 trial uses an open-ended assessment of questions that reflect the required elements of informed consent according to the US Code of Federal Regulations. Within each of these items are more specific elements. These are "must knows" that volunteers are required to answer correctly in order to be enrolled.

\begin{tabular}{|c|c|c|c|}
\hline $\begin{array}{l}\text { Open-Ended } \\
\text { Questions/Statement }\end{array}$ & Required Points of Comprehension & $\checkmark$ & Comments \\
\hline \multirow{4}{*}{$\begin{array}{l}\text { 1. Please describe your } \\
\text { understanding of the } \\
\text { purpose of the study. }\end{array}$} & Study is testing two experimental gels & & \\
\hline & Testing to know if gels are safe & & \\
\hline & Testing to learn if gels may prevent HIV & & \\
\hline & Study may not prove gels work & & \\
\hline \multirow{4}{*}{$\begin{array}{l}\text { 2. What do you understand } \\
\text { that you are being asked } \\
\text { to do in this study? }\end{array}$} & $\begin{array}{l}\text { Asked to use condoms and perhaps gel with } \\
\text { each act of vaginal sex }\end{array}$ & & \\
\hline & Have pelvic exams and HIV tests & & \\
\hline & Come for monthly visits for up to 30 months & & \\
\hline & Not get pregnant in next 30 months & & \\
\hline \multirow{3}{*}{$\begin{array}{l}\text { 3. What do you understand } \\
\text { about possible risks that } \\
\text { might happen as a result } \\
\text { of being in the study? }\end{array}$} & Gel may irritate skin inside or outside vagina & & \\
\hline & Gel may have other side effects & & \\
\hline & Possibility of social harms & & \\
\hline \multirow{2}{*}{$\begin{array}{l}\text { 4. What will happen to you } \\
\text { if you decide not to join } \\
\text { the study? }\end{array}$} & Free to make own decision about joining & & \\
\hline & $\begin{array}{l}\text { No effect on access to care when decide to } \\
\text { join or not }\end{array}$ & & \\
\hline \multirow{3}{*}{$\begin{array}{l}\text { 5. Please tell me about the } \\
\text { different groups of } \\
\text { women in the study. }\end{array}$} & There are different gels & & \\
\hline & Not everyone receives a gel & & \\
\hline & No one knows who receives which gel & & \\
\hline \multicolumn{4}{|l|}{ Outcome: } \\
\hline \multicolumn{4}{|c|}{$\square$ Demonstrated comprehension of all required points, decided to enroll in study. } \\
\hline \multicolumn{4}{|c|}{$\square$ Demonstrated comprehension of all required points, decided NOT to enroll in study. } \\
\hline \multicolumn{4}{|c|}{$\begin{array}{l}\square \text { Demonstrated comprehension of all required points, deferred enrollment decision to } \\
\text { another visit. }\end{array}$} \\
\hline \multicolumn{4}{|c|}{$\begin{array}{l}\square \text { Did not demonstrate comprehension of all required points (yet), needs more time/discussion, } \\
\text { rescheduled for another visit. }\end{array}$} \\
\hline \multicolumn{4}{|c|}{$\square$ Unable to demonstrate comprehension of all required points, consent process discontinued. } \\
\hline \multicolumn{4}{|l|}{ Staff signature: } \\
\hline
\end{tabular}

Source: A.S. Coletti. 2005. "HPTN 035 informed consent comprehension assessment." Presentation at the Population Council/Family Health International Workshop on Informed Consent in HIV Prevention Trials, New York, 16-18 May. 
